\title{
Children's Exposure to Violence
}

\author{
Valerie Maholmes $\cdot$ Ronald J. Prinz
}

Published online: 11 March 2009

(C) Springer Science+Business Media, LLC 2009

Beginning with the current issue, Clinical Child and Family Psychology Review is devoting two special issues (Volume 12 , Issues $1 \& 2,2009$ ) to research themes and developments in the area of children's exposure to violence. These issues come 6 years after the journal's special issues in 2003 reviewing and setting the agenda for research on children's exposure to domestic violence, community violence, war, and terrorism. The articles featured in the 2003 issues represented a distillation of a federally sponsored 3-day conference held in 2002 on children exposed to violence where prevalence, consequences, services, and interventions were discussed (Feerick and Prinz 2003a; Prinz and Feerick 2003a). The papers presented at the 2002 conference underscored the need for systematic study of child violence exposure. The conference planners put forward recommendations for an agenda for research, policy, and practice to find effective ways to prevent violence and ultimately eliminate children's exposure to violence. Some of the recommendations, outlined in the 2003 special issues (Feerick and Prinz 2003b; Prinz and Feerick 2003b), included:

- the need to utilize the best models, methods, and instruments to study exposure to violence

- the need to study the ecological context within which the child develops; the types of violence that occurs in these contexts and how these experiences with and

\footnotetext{
V. Maholmes

Eunice Kennedy Shriver National Institute of Child Health and Human Development, Rockville, MD, USA

e-mail: maholmev@mail.nih.gov
}

R. J. Prinz ( $\square)$

University of South Carolina, Columbia, Sc, USA

e-mail: PRINZ@mailbox.sc.edu exposure to these types of violence affect child and family functioning

- more research on early intervention and prevention for children at risk for later problems due to exposure to domestic and other forms of violence

- the need for research that takes on a developmental perspective and that elucidates the short- and long-term outcomes of children at different ages and stages of development

- more extensive data on the prevalence of types of violence-how often it occurs, where it occurs, and who is at greatest risk for experiencing these types of violence

- identify factors of resilience as well as risk to understand the roles of schools, communities, and families in ameliorating or exacerbating the effects of violence exposure.

In response to the 2002 conference and the articles highlighted in the 2003 special issues, the National Institute of Child Health and Human Development took the lead at the National Institutes of Health in putting forward a special call for applications (PAR-03-096) focused on research on children exposed to violence with a goal toward developing a scientific understanding of the incidence, prevalence, nature, and consequences of exposure to violence. Despite the public health significance of child exposure to violence, it was the view of the federal agencies involved that progress had been slow in fostering these understandings and yielding solid evidence upon which interventions to prevent or reduce the effects of violence exposure on child development could be based. Furthermore, research had been hampered by methodological issues and constraints including sampling and recruitment difficulties, ethical, and reporting challenges, co-occurrence of multiple types of violence 
exposure and victimization experiences, and a failure to account for other family background or risk variables. Thus the call for applications sought to encourage research on the incidence, prevalence, nature, and consequences of child exposure to violence, as well as on interventions (including social service, legal, and policy interventions) designed to prevent or ameliorate the shortand long-term effects of violence exposure on child development.

The results from this special solicitation were many cogent research projects, several of which are represented in the articles of the 2009 special issues. In the past 6 years, this area has progressed and the scientific work has become more sophisticated. The articles cover several areas of violence and trauma including intimate partner violence, parent-to-child aggression, community violence, natural disasters (e.g., Hurricane Katrina), terrorist-produced violence (e.g., the World Trade Center), and political and warrelated violence. The range and depth of topics in the articles is apparent. The work represents advances in assessment of children's violence exposure, stress process models taking into account family and community violence, understanding children's emotional and physiological reactivity and regulation as intermediary processes, conceptualizations that take into account broader social-ecological context to determine the impact of political violence, evaluating how children with disabilities are affected by violence exposure, describing the impact of violence on health and parenting, factoring in multiple sources of violence exposure over time, and the treatment of traumatized children.

Collectively, the articles in these two issues of Clinical Child and Family Psychology Review on children's exposure to violence mark the field's developments and help to set the agenda for the next several years of research.

\section{References}

Feerick, M. M., \& Prinz, R. J. (2003a). Introduction to special issue on children's exposure to domestic violence. Clinical Child and Family Psychology Review, 6, 147-149.

Feerick, M. M., \& Prinz, R. J. (2003b). Next steps in research on children exposed to community violence or war/terrorism. Clinical Child and Family Psychology Review, 6, 147-149.

Prinz, R. J., \& Feerick, M. M. (2003a). Children exposed to community violence or war/terrorism: Current status and research directions. Clinical Child and Family Psychology Review, 6, 221-222.

Prinz, R. J., \& Feerick, M. M. (2003b). Next steps in research on children's exposure to domestic violence. Clinical Child and Family Psychology Review, 6, 215-219. 